\title{
Igualdad como Emancipación: Los Derechos Fundamentales de los Pueblos Indígenas
}

Este artículo se encuentra disponible en www.anuariocdh.uchile.cl

Silvina Ramírez*

\section{Introducción}

El concepto de igualdad que actualmente maneja la filosofía política es insuficiente para dar cuenta, desde una perspectiva crítica, del estado de situación de los pueblos indígenas. Su condición de vulnerabilidad y su evidente desventaja con respecto a la "sociedad mayor" señalan la necesidad de desarrollar nuevas categorías que puedan contribuir a transformar esa realidad para la construcción de sociedades más igualitarias.

Tanto los enfoques liberales como los enfoques fundamentalistas, ambos integradores de dimensiones morales y políticas, no han podido enfrentar satisfactoriamente el desafío de diseñar con sus aportes sociedades que tengan como eje el principio de igualdad, generando escenarios donde los acuerdos, el consenso y el diálogo entre los distintos sujetos -individuales y colectivos- sean posibles.

Las posiciones liberales, mediante procesos de abstracción que sólo demuestran una "ilusión de trascendentalidad"1, no descubren el grado y profundidad de las desigualdades concretas que hoy existen, ni ofrecen herramientas efectivas para superarlas.

Las posiciones fundamentalistas, desde una mirada contraria, crean situaciones similares al absolutizar rasgos que son, paradójicamente, particulares. A pesar del relativismo cultural que aparentemente defienden (en donde todo plexo axiológico es admisible), sólo consideran como valioso aquello que se encuentra en el ámbito de su concepción particular.

Por ello es imprescindible pensar en un concepto nuevo y superador, que no universalice ni absolutice, y que cuente con cierta plasticidad para adaptarse a las más variadas situaciones. A través de una propuesta que conjugue diferentes niveles de análisis, presentaré algunas ideas que clarifiquen el marco de la discusión y que signifiquen un aporte concreto en la lucha por la igualdad de los pueblos indígenas.

Así, en este trabajo describiré brevemente los conceptos de igualdad formulados desde las perspectivas liberales y fundamentalistas (II); exploraré, a través de otras categorías, la construcción de un nuevo y superador concepto de igualdad que refleje las relaciones sociales de los sujetos históricamente situados (III); defenderé una idea particular de los derechos de los pueblos indígenas -derechos emancipatorios-y presentaré razones que permitan ubicarlos jerárquicamente

\footnotetext{
* Directora Ejecutiva del Instituto de Estudios Comparados en Ciencias Penales y Sociales (INECIP), Argentina. Profesora de Derecho Constitucional en la Facultad de Derecho de la Universidad Nacional de Buenos Aires.

1 En este ensayo utilizo la idea de "ilusión de trascendentalidad" para referirme a la pretensión de construir conceptos -que no son meramente formales- al margen del contexto y de la historia. Al respecto, existe una sólida corriente de pensamiento que no puede concebir la construcción de conocimiento por fuera de la historicidad. En ese sentido, ver Vattimo, Gianni, Introducción a Heidegger, Ed. Gedisa, Barcelona, 1986, p. 27; Grondin, Jean, Introducción a la Hermenéutica Filosófica, Ed. Herder, Barcelona, 1999, pp. 162-165.
} 
sobre otros derechos reconocidos por el Sistema Internacional de los Derechos Humanos (IV). Finalmente, y por medio de la descripción de herramientas normativas e institucionales concretas, relacionaré el nuevo paradigma de igualdad defendido con la situación cotidiana de los pueblos indígenas $(\mathrm{V})$.

\section{Un concepto (reduccionista) de igualdad}

La igualdad como idea, como concepto, como horizonte está presente en los debates iusfilosóficos desde los últimos cuatro siglos. Tanto por la necesidad de explicar y justificar sociedades que siempre han sido desiguales, como por la de revelar fenómenos que han tomado cada vez más peso, tales como la diversidad en materia cultural, étnica, religiosa, sexual, de género, etcétera. Lo cierto es que el principio de igualdad ha transitado varios canales de discusión y ha sido asumido de diferentes maneras por las distintas teorías.

Sin embargo, más allá de esta omnipresencia, teóricamente no se ha podido formular un concepto claro que pueda superar tanto las insuficiencias de los enfoques liberales de análisis como de los fundamentalistas, que en las más diversas áreas son profundamente refractarios -paradójicamente- a lo distinto ${ }^{2}$. En la práctica, tampoco se ha avanzado demasiado en alcanzar sociedades más igualitarias. Ni las ambiciosas teorías liberales del último medio siglo, ni las más contemporáneas miradas sobre este problema han logrado dar el salto que la igualdad-como idea eje y basamento de cualquier institución democrática- requiere ${ }^{3}$.

La libertad y la igualdad han sido presentadas, desde la perspectiva liberal, como conceptos medulares pero ordenados jerárquicamente. Al establecer, entonces, prioridades inconsecuentes, centrando el debate en la determinación de si la libertad prevalece sobre la igualdad o viceversa, se ha llegado a callejones sin salida que poco aportan a la discusión central alrededor de los pueblos indígenas y su relación con el principio de igualdad.

La construcción de un nuevo sentido de este principio responde a la necesidad de organizar un diálogo distinto entre la sociedad occidental y los pueblos indígenas, partes que se enfrentan, finalmente, en la disputa por la conquista de derechos. Ello, a fin de que la formulación clásica de la idea de "ser tratados con igual consideración y respeto" sea mayormente sensible a las diferencias y derive consecuencias prácticas que favorezcan a los pueblos indígenas.

La libertad y la igualdad indudablemente son dos características insoslayables en nuestras organizaciones, que deben primar en el desarrollo de las instituciones democráticas. Ahora bien, estos ejes incorporados a la mejor marcha de las "sociedades occidentales" no funcionan necesariamente del mismo modo cuando nos encontramos frente a pueblos indígenas, cuyas instituciones están construidas sobre la base de valores diferentes.

La igualdad se transforma, en este caso y para los pueblos indígenas, en una condición para el ejercicio de la libertad. La igualdad se presenta como un valor tan relevante como la libertad, y es a partir de este supuesto que podemos intentar la construcción de un principio con un contenido diferente al clásico.

\footnotetext{
Piénsese en el feminismo radical, en el relativismo cultural, o en el fundamentalismo étnico para advertir la clase de mirada a la que hago referencia.

3 Para profundizar en los temas de igualdad desde las teorías liberales se pueden consultar, entre otros: Rawls, John; Sen, Amartya y otros, Libertad, igualdad y derechos, Ed. Planeta-Agostini, Barcelona, 1994; Nagel, Thomas, Igualdad y parcialidad. Bases éticas de la teoría política, Ed. Paidós, Barcelona, 1991.
} 
Bien dice Gray ${ }^{4}$ que no podemos tratar a las personas de formas iguales a menos que sepamos cuáles son sus intereses. Los conflictos de intereses que se erigen sobre conflictos de valores plantean una crítica muy fuerte al principio de igualdad entendido desde una perspectiva liberal. No puede concebirse ni aplicarse este principio de manera universal, como tampoco puede pensarse que "el tratamiento semejante" involucre la satisfacción de bienes idénticos para todos.

Para los pueblos originarios el trato igualitario tiene mucho más que ver con la justicia en la distribución de recursos (y no de cualquier recurso) que con la satisfacción de otras necesidades. Así, encontramos en la literatura tradicional un principio bifronte de igualdad. Una de sus caras apunta al tratamiento semejante, con lo cual la diferencia se diluye y se equiparan -por ejemplo- las necesidades de un ciudadano miembro de un pueblo originario con las de un ciudadano perteneciente a la cultura occidental. La otra cara apunta al tratamiento paternalista, del que se deriva una atención particular al indígena -como individuo, sin registrar la importancia del "pueblo" en la conformación de su identidad-, que finalmente se traduce en el menoscabo de la diferencia a partir de la clara intención de subsumirlo en los valores liberales. En otras palabras, no se toma en serio la diversidad que representa a los pueblos indígenas y los valores inherentes e inescindibles de su condición de pueblos.

Si hacemos el ejercicio de entrecruzar los conceptos clásicos alrededor del principio de igualdad con los derechos exigidos por los pueblos indígenas a los Estados, podemos advertir rápidamente que el análisis tradicional es insuficiente para satisfacer dichos derechos básicos, y menos aún, para construir Estados donde indígenas y no indígenas efectivamente se encuentren en un pie de igualdad.

Esto así presentado tampoco es producto del azar ni de la naturaleza humana. El principio de igualdad, formulado en abstracto, se encuentra en permanente tensión con su posibilidad de concreción. De ese modo, la construcción de sociedades igualitarias está desafiada por el delicado equilibrio que debe producirse para evitar posturas paternalistas, que conciben la igualdad como un conjunto de concesiones, y para evitar aquellas individualistas, cuya concepción enraizada en las teorías liberales las remite sin más a un desconocimiento, ignorancia y desprecio de lo distinto.

Frente a este panorama, es interesante entonces dilucidar los sentidos de igualdad utilizados y enfrentados a dos concepciones antagónicas, el universalismo y el particularismo, de las cuales han abrevado tanto liberales como fundamentalistas. Desde su génesis, la universalidad ha estado ligada a la igualdad y vinculada fuertemente a la noción de una razón universal rectora de los destinos de las personas. Por su parte, el particularismo ha entendido el principio de igualdad como aquel que percibe y respeta los diferentes "modus vivendi".

Los pueblos indígenas siempre transitan esta dicotomía que traspasa las reflexiones teóricas para generar efectos prácticos de importancia, a partir de que una y otra concepción construyen marcos de interacción cuya consecuencia es igualar, desde determinados parámetros y valores, o respetar el pluralismo axiológico existente.

En esta línea de análisis, describiremos (de manera también reduccionista, vale la pena confesar) dos miradas que pretenden superar exitosamente el "hecho de la diversidad", pero que desembocan inevitablemente en caminos sin salida, incapaces de servir como fundamento a las demandas de los pueblos indígenas.

4 Gray, John, Las dos caras del liberalismo. Una nueva interpretación de la tolerancia liberal, Ed. Paidós, Barcelona, 1991, p. 107. 


\section{El universalismo y los enfoques liberales}

Sin lugar a dudas, uno de los pilares del liberalismo actual, a partir del cual se han derivado numerosos debates, es John Rawls. Su principal obra, "Teoría de la Justicia"5, ha significado un punto de inflexión en las discusiones contemporáneas y ha provocado un sinnúmero de escritos posteriores.

No es objetivo de este trabajo llevar adelante un análisis exhaustivo de su obra ni señalar una a una sus críticas. Sólo enfatizar que a partir de sus dos principios de justicia, las ideas de libertad e igualdad han tomado una mayor pero diferente fuerza.

En Rawls, es principalmente la concepción de la libertad individual el valor por excelencia, frente al cual no es posible ceder demasiado terreno. Sin embargo, no sucede lo mismo con su noción de igualdad. Ésta puede ceder, de acuerdo a su segundo principio de justicia, si las desigualdades producidas son en beneficio de los más desaventajados 6 . A primera vista, este segundo principio de justicia parecería corregir los graves defectos de las teorías liberales, teorías que no han dado mucho espacio a la idea de igualdad. No obstante, el mismo Rawls sostiene que los principios de libertad e igualdad están organizados en un "orden lexicográfico, según el cual el principio de libertad tiene prioridad sobre el de la diferencia. El principio de igualdad, entonces, no tiene cabida si con antelación no se respeta el principio de libertad. De esta manera, la igualdad siempre queda ensombrecida por una concepción que consagra la preeminencia absoluta de la libertad" ${ }^{\prime 7}$.

Entonces, esta teoría no ofrece respuestas concretas a las necesidades básicas y demandas de los pueblos originarios. Muchas veces es preciso hacer sustanciales concesiones de libertad para reparar desigualdades sociales o económicas. Y la rígida postura rawlsiana, aún con su principio de diferencia, subordina la idea de igualdad a otro principio supremo y, como tal, hace imposible cualquier esfuerzo de distribuir un poder igual en una sociedad de por sí desigual.

A su vez, el aspecto que se presenta como más débil y vulnerable en su teoría es el de la posición originaria y el supuesto acuerdo abstracto que, precisamente por sobredimensionar la universalidad, deja de lado la diversidad. Al utilizar el velo de la ignorancia como herramienta para la formulación de los principios de justicia, necesariamente excluye las características socioculturales, la diversidad, la identidad como tal. Diluir las diferencias es el precio que Rawls debe pagar para alcanzar un consenso unánime entre personas. Por ello, resulta clara la preeminencia de la libertad y los derechos individuales sobre la igualdad y los derechos colectivos o de grupo. Tal como lo afirma Díaz-Polanco "...los liberales igualitarios pueden sostener que los derechos socioculturales o de grupos (en los casos que admiten su existencia) son, en realidad, derechos adjetivos: una extensión de los individuales. La adjetividad de lo colectivo depende de la sustantividad de lo individual" ${ }^{8}$.

En definitiva, considero que la teoría de la justicia de Rawls y el concepto liberal de igualdad no tienen cabida para reconocer la diversidad de los pueblos indígenas. El "hecho de la diversidad" queda diluido frente a valores cuya universalidad no se discute. $Y$ la carencia de la perspectiva

\footnotetext{
Rawls, John, La Teoría de la Justicia, María Dolores González (trad.), 2ª ed., Ed. FCE, México, 1995.

6 El segundo principio de la Teoría de Justicia de Rawls se formula de la siguiente manera: "Las desigualdades económicas y sociales han de ser estructuradas de manera que sean para: a) mayor beneficio de los menos aventajados, de acuerdo con un principio de ahorro justo, y b) unidos a los cargos y las funciones asequibles a todos, en condiciones de justa igualdad de oportunidades".

7 Díaz-Polanco, Héctor, Elogio de la Diversidad: globalización, multiculturalismo y etnofagia, Siglo XXI, México, 2006, pp. 79-83.

8 Díaz-Polanco, Héctor, op. cit., p. 85.
} 
historicista de la teoría rawlsiana (al menos en el primer Rawls) debe ser superada y subsanada a los efectos de construir un genuino y superador concepto de igualdad.

A pesar de que en su segunda gran obra, "Liberalismo Político" ${ }^{9}$, Rawls intenta defender su teoría de justicia, y responder a sus críticas, lo cierto es que transitar de una teoría metafísica a una política socava a la primera y deja sin resolución y sin fundamentos a la segunda. Debe reconocerse que incorpora una perspectiva historicista al contextuar la teoría, resignando parte de su universalismo original. Sin embargo, la ambivalencia que conserva no permite explicar adecuadamente la inserción del pluralismo en las sociedades modernas. Si bien no se desconoce la pluralidad de valores, se pretende que todos -en algún momento y de alguna manera- sean convocados a vivir bajo el paraguas de valores pretendidamente universales. La igualdad así entendida, como un principio universal, sólo tolerará lo diferente pero no lo admitirá dentro de su universo. La insistencia en asumir la existencia de una razón universal lleva al autor a englobar todo en determinados valores liberales, que en definitiva tendrán la última palabra.

En este sentido, los liberales - con las generalizaciones del caso, pero me estoy refiriendo específicamente a los liberales igualitarios, dado que los liberales libertarios o no pluralistas directamente desconocen el problema- desarrollan un concepto insuficiente para responder a las necesidades, demandas y derechos de los pueblos indígenas en cuanto a su reconocimiento y su trato igualitario ${ }^{10}$.

El reconocimiento de lo diferente involucra mucho más que la aceptación "en abstracto" de la igualdad de las personas. Comprende mucho más en la medida en que el desafío está constituido precisamente por dimensiones valorativas diferentes y, en gran medida, inconmensurables ${ }^{11}$.

Si se consideran los valores liberales como parámetros de lo correcto, y más allá que se intente -estos autores lo hacen- dejar de lado las concepciones del bien para formular una teoría procedimental y no sustantiva, las miradas liberales sólo toleran débilmente lo que no se adecua a ellas. De ese modo la igualdad que se predica es más bien retórica y no alcanza a concretar el respeto irrestricto por lo que los/as "otros/as" consideran valioso.

En definitiva, a pesar de los intentos que se han Ilevado adelante para cerrar las brechas que profundizan las diferencias conceptuales, el enfoque liberal no puede nutrir su concepto de igualdad de modo que abarque tanto los valores liberales como los que no lo son, y por ello tampoco admite la existencia de derechos colectivos (salvo que estos no atenten contra las concepciones de lo correcto que manejan $)^{12}$.

Los pueblos indígenas, dentro de este paradigma, son considerados un conjunto de individuos que deben ser respetados en cuanto gozan de derechos humanos, pero siempre y cuando respondan a un modelo consensuado universalmente. Sus requerimientos como colectivo quedan fuera de ese "tratamiento igualitario" invocado por las teorías clásicas de la igualdad.

El principio de igualdad frente a la universalidad sólo se entiende dentro de un único marco valorativo. La asimilación y semejanza son conceptos que van de la mano de esta mirada, que

9 Rawls, John, El liberalismo político, S.R. Madero Báez (trad.), Ed. FCE, México, 1995.

10 Sobre el liberalismo y sus diferentes corrientes se puede consultar: Farrell, Martín, La filosofía del liberalismo, Centro de Estudios Constitucionales, Madrid, 1992; Gargarella, Roberto, Las teorías de la justicia después de Rawls. Un breve manual de filosofía política, Ed. Paidós, Barcelona, 1999.

11 Para una discusión sobre la inconmensurabilidad de los valores ver Gray, John, op. cit., 2001.

12 Uno de los autores contemporáneos referentes de este esfuerzo teórico para acortar las distancias entre las diferentes posturas es Will Kymlicka. Ver Kymlicka, Will, Ciudadanía Multicultural. Una teoría liberal de los derechos de las minorías, C. Castells Auleda (trad.), Ed. Paidós, Barcelona, 1996. 
convierte el ejercicio concreto de este principio en el pálido reflejo de un pensamiento ideal en donde la diversidad ocupe un lugar central.

Consciente de que estas críticas así expuestas son muy superficiales, pero queriendo dejar sentado en estas pocas hojas una postura que ponga de relieve la complejidad de la diversidad cuando se enfrenta al principio de igualdad, me referiré a continuación a una teoría de signo contrario, que tampoco puede afrontar los desafíos señalados.

\section{El particularismo y el enfoque fundamentalista (o relativista cultural absoluto)}

El ya muy conocido proverbio del "todo vale" que representa a las corrientes relativistas no contribuye a dotar de solidez y fundamento al hecho de lo diverso. Ello, a pesar de que estos enfoques, en términos generales, consideren que no existe un sistema de creencias y valores sobre otros, que debe admitirse cualquier postura, y que no existen parámetros plausibles de corrección.

Desafortunadamente, lo que en apariencia se presenta como un respeto ilimitado a la diversidad, termina generando sistemas cerrados, que dan la espalda a quienes se considera "los/as otros/as", para centrarse sólo en el universo en el que están inmersos. De esa manera, y en materia indígena por ejemplo, se desarrolla lo que se conoce como fundamentalismo o esencialismo étnico, que no es otra cosa que una mirada que sólo reconoce como valioso lo asentado en concepciones indígenas ${ }^{13}$.

Los así llamados fundamentalismos étnicos socavan cualquier intento de desarrollar instituciones democráticas y finalmente terminan por debilitar lo que en apariencia fortalecen. La diversidad no encuentra lugar en esta concepción, que admite "un único hecho diverso" y que configura cierto racismo; de otro signo, pero racismo al fin.

En definitiva, los enfoques relativistas no pueden aportar ningún elemento a un desarrollo más sustancioso del principio de igualdad, no contribuyen a alcanzar una sociedad más equitativa y resultan tan insuficientes -de cara a los pueblos indígenas- como los enfoques liberales ${ }^{14}$.

El principio de igualdad debe ser algo más que el producto de una razón universal que mediante un proceso de abstracción genera situaciones que no son más que ficciones. También debe superar posturas que, alejadas de cualquier posibilidad de diálogo y de acuerdo, sólo consideran sus propios valores e imaginan amenazas frente a cualquier intento de universalización.

Por ello, el gran desafío para una construcción adecuada del principio de igualdad es la diversidad. La diversidad entendida desde lo fáctico, como "el hecho de la diversidad", aquel fenómeno social que se presenta en las sociedades contemporáneas cada vez con más fuerza y que es una evidencia concreta de las dificultades que enfrentan las teorías clásicas.

\section{Un concepto (genuino) de igualdad (1)}

Como se dijo, los ideales de una razón universal, de un tratamiento "semejante" basado en supuestos denominadores comunes a todas las personas, y de principios que sustentan las teorías liberales y que predican su aplicación en todo tiempo y lugar con un grado de abstracción considerable y sin tomar en cuenta la realidad de lo diferente, conspiran contra el afianzamiento de

13 Díaz-Polanco, Héctor, op. cit. Dice el autor: “...el primer riesgo es, entonces, que la realización política de la diversidad se manifieste como atrincheramiento de identidades e incluso como hostilidad entre culturas. La postulada inconmensurabilidad cultural se concretaría en irreductibilidad política. Y sin arreglo político en la pluralidad, sin convivencia respetuosa y tolerancia, no hay régimen autonómico posible" (p. 29).

14 Díaz-Polanco, Héctor, op. cit., pp. 22-23. 
modos de vida asentados en valores muchas veces inconmensurables. Sus esfuerzos se vuelven insuficientes porque la ausencia de una mirada histórica no permite merituar lo que es relevante en cada tiempo y situación.

Con todo, esta interpretación posible del principio de igualdad ha dominado las discusiones teóricas de los últimos siglos. Sin embargo, no termina de digerir que existen visiones del mundo que no responden a un solo paradigma, y que no colocan "lo individual" en el centro de su cosmovisión. Este pecado capital ha desatado una verdadera "caza de brujas" contra cualquier reclamo colectivo, sólo atemperada por algunas posturas liberales ${ }^{15}$ que han intentado -e intentan- generar puentes entre las diferentes miradas alrededor de la cláusula igualitaria.

Lo cierto es que a pesar de estos intentos existen voces que reclaman un tratamiento igualitario y no discriminatorio que involucre no sólo la libre elección de planes de vida alternativos sino un desarrollo de otros derechos que posibiliten su consecución. El tratamiento igualitario, que a la vez respete la diversidad, debe entonces entenderse como aquel que requiere de tres cuestiones básicas. Por una parte, la no obstaculización del despliegue del plan de vida elegido, y en ese sentido la garantía de no discriminación. Por otra parte, la realización de acciones positivas que aseguren el desarrollo y la protección de algunos derechos imprescindibles para llevar adelante dicho plan. En tercer lugar, una particular preocupación por situar históricamente a personas y colectivos.

En el caso de los pueblos indígenas, la igualdad no significa otra cosa que un "tratamiento diferencial", que tenga presente diferentes concepciones y que se enmarque en un contexto histórico. Ello lleva claramente a la admisión de la existencia de otros valores, tal vez muy alejados de los que imperan en la "sociedad mayor".

En definitiva, los sujetos colectivos que se van perfilando requieren para el acceso a sus derechos de un principio de igualdad con contenido, que les permita profundizar sus conquistas dentro de un determinado proceso histórico que sitúa sus demandas y legitima sus luchas. Un principio de igualdad que sólo sea un armazón, carente de un significado político que justifique la existencia de determinados derechos, constituye un fundamento débil para la construcción de una sociedad democrática y vacía de contenido a los procesos de conquista de derechos.

\section{Lerarquías y valores en el sistema internacional de los derechos humanos}

Tal vez uno de los desafíos teóricos más estimulantes y complejos para su operatividad sea conjugar el sistema de los derechos humanos reconocidos internacionalmente con el principio de igualdad, principalmente porque estos derechos que han sido consensuados por gran parte de los Estados tampoco representan cabalmente aquellos que reclaman los pueblos indígenas.

Los derechos humanos reconocidos internacionalmente están basados principalmente en la individualidad. Surgieron como producto de grandes luchas por proteger a las personas de violaciones cometidas por los Estados. Es desde esa perspectiva que existe un énfasis en determinados valores y en su pretendida universalidad, que sobrevuela una concepción "liberal individualista" que no contribuye a sedimentar y fortalecer la diferencia.

Así, lo relevante del análisis e ideas centrales de este trabajo gira alrededor de la necesidad de jerarquizar ciertos valores al momento de elaborar sistemas que comprenden cosmovisiones diversas y no comparables. Para la construcción de dicha jerarquía, los valores deben ser sopesados tomando en consideración elementos tales como el contexto, la perspectiva histórica, el sistema

\footnotetext{
15 Kymlicka, Will, op. cit., Barcelona, 1996.
} 
cultural y de creencias, entre otros. Asimismo, esta construcción debe hacerse destacando al menos dos diferencias.

La primera constituye una diferencia sustantiva notable entre los valores comprendidos en el sistema internacional de los derechos humanos y los valores comprendidos en las concepciones indígenas (sin negar, obviamente, que también existen valores compartidos) ${ }^{16}$. Si bien cada vez más se organizan mesas de trabajo que, en el nivel de las discusiones internacionales, incorporan representantes indígenas y que, por otra parte, el sistema de derechos humanos "occidental" ha intentando en el último medio siglo incorporar otras miradas y concepciones, lo cierto es que los valores imperantes distan de representar las creencias, necesidades y demandas de los pueblos originarios, simplemente porque han sido generados en contextos disímiles.

La segunda diferencia de importancia debe establecerse teniendo presentes los matices que poseen los distintos pueblos indígenas, que no representan otra cosa que la expresión de una variedad de sistemas culturales, políticos, religiosos, etcétera. Los pueblos indígenas reclaman para sí reconocimiento y respeto de ciertos derechos basados en determinados valores. Pero si bien para reducir la complejidad hablamos de "pueblos indígenas" en general, los diferentes pueblos que son parte de lo "indígena" conforman un crisol difícilmente asimilable y carente de las semejanzas que a simple vista se supone deberían existir.

No es lo mismo el pueblo aymara que el pueblo quechua, como tampoco se asemeja el pueblo mapuche al pueblo guaraní. Todos ellos, aunque imbuidos de una mirada común sobre ciertos temas, presentan distinciones importantes que también deben ser tenidas en cuenta a la hora de pensar en un reconocimiento y respeto que trascienda lo moral, que vaya más allá de algunas reglas, y que pueda ser trasladado claramente a la dimensión política. Cuando hablamos de "pueblos indígenas" sólo damos un primer paso hacia un "universo diverso" que debe ser profundizado.

No obstante, y sólo a efectos de evidenciar la densidad que adquiere este análisis, vale la pena seguir otras vías de reflexión. Así, debemos incorporar la variable temporal y contextual a nuestro análisis. En otras palabras, es ineludible hacernos cargo de que existen multiplicidad de valores, que éstos se ordenan jerárquicamente, que esta jerarquía está estrechamente relacionada con los sistemas culturales y políticos, y que a su vez dependen de ciertos contenidos temporales que toman distancia de la vieja fórmula "válidos en todo tiempo y lugar".

No se trata de dar la espalda a la universalidad de los derechos humanos bien entendida. De lo que se trata es de entender el sistema de derechos humanos como un conjunto de valores morales, traducidos en un marco normativo y trasladados a una dimensión política, que tienen validez en un tiempo determinado, y cuya jerarquía no sólo tiene relación con parámetros individualistas, sino que debe tenerse presente otro tipo de valores asentados en referentes colectivos de igual o mayor peso que los primeros.

Los sujetos colectivos, como tales, se asientan en valores que no necesariamente coinciden con lo que es valioso para las personas en su individualidad. Pero en la lucha por los derechos, en los procesos de conquista, han sido precisamente los sujetos colectivos los que se han destacado y quienes se convirtieron en referentes para finalmente alcanzar el reconocimiento de esos derechos.

16 Es muy ilustrativo rever las concepciones vertidas por reconocidos referentes políticos y sociales en el proceso de discusión de la Declaración de los Derechos del Hombre. Así, el núcleo central de las discusiones lo constituye la "necesidad histórica" de universalizar valores, para defender a los seres humanos de las potenciales violaciones de los Estados. Ver: Los Derechos del Hombre. Estudios y Comentarios en torno a la Nueva Declaración Universal, Ed. FCE, México, 1949. 
No se puede pasar por alto esta realidad constatada históricamente, reduciendo las cuestiones de derechos a problemas atinentes sólo a personas consideradas aisladamente.

Obviamente, este análisis nos conduce a rechazar "lo universal" como una categoría abstracta, lo que no significa comprometernos con la admisión de cualquier sistema valorativo, que implique adscribir irremediablemente a tesis relativistas. Precisamente para alcanzar este equilibrio sutil es que se sugiere llevar adelante una ordenación de valores de acuerdo a las circunstancias específicas a las que se ven sometidos algunos colectivos vulnerables o con características específicas, que por su condición merecen ser tratados "diferencialmente" para honrar un principio robusto de igualdad.

\section{Perspectiva historicista}

Tal vez una de las principales distorsiones que produce el sistema internacional de derechos humanos es su pretensión de universalidad, cuyas categorías traspasan tiempo y espacio a la vez que intentan representar el común denominador de toda la humanidad.

En realidad, se pretende construir un sistema que no tenga presente la perspectiva histórica, que no se encuentre situado y contextualizado, que se abstraiga del tiempo histórico en el que se desarrolla. Un sistema de ficción, sin raigambre, sentido y posibilidades de fundamentar su génesis y desarrollo ${ }^{17}$.

Este es el punto que quiero destacar. La trascendentalidad de la que echan mano muchas de las teorías formales del derecho para explicar fenómenos de generalización o universalización se enfrenta radicalmente con las visiones historicistas. La tensión es clara y fácilmente explicable: para estas últimas visiones es muy difícil transmitir la idea de una persona carente de pasado, sin historia, sin contexto, sin cultura. La trascendentalidad genera la ilusión de personas que están más allá de su tiempo y de su espacio, desembocando en un absoluto que no puede explicar ni justificar las demandas de los pueblos indígenas por una sociedad igualitaria.

Las perspectivas historicistas ${ }^{18}$ han insistido permanentemente en transmitir la importancia del devenir en los procesos de gestación de los productos sociales. Los derechos humanos no escapan de ello, y sin caer en una perspectiva relativista simplista, para diluir su carácter abstracto y dotarlos de plena efectividad y vigencia resulta imprescindible diseñar un sistema de valores que sea flexible a las diferentes realidades.

Frente a la necesidad de combinar perspectivas dicotómicas, se imponen algunas aclaraciones. Estas ideas no significan sostener prescriptivamente que los derechos de una época determinada deben privilegiarse sobre otros porque descriptivamente así haya acontecido o efectivamente esté sucediendo (falacia naturalista). Tampoco implican establecer que las elecciones de valores se Ileven adelante aleatoriamente, generando sistemas ad hoc que dependan azarosamente del tiempo y del contexto.

17 Es interesante reflexionar sobre otras conceptualizaciones de los derechos humanos, que enfatizan una "perspectiva liberadora". Así "....Dar carne histórica y social al tema de los derechos humanos (....) no puede ser realizado con el suficiente rigor y honestidad intelectual si no se explicita el "desde dónde" se consideran y el "para quién" y "para qué" se proclaman dichos derechos. Nos propone que ese desde dónde y ese para quién-para qué sean "los pueblos oprimidos y las mayorías populares". Alvarado, Rolando, "Derechos Humanos y mundialización”, en Travesías. Política, Cultura y Sociedad en Iberoamérica, Universidad Internacional de Andalucía, Huelva, julio-diciembre de 2006.

18 Perrot, Dominique y Preiswerk, Roy, Etnocentrismo e Historia. América Indígena, África y Asia en la visión distorsionada de la cultura occidental, Ed. Nueva Imagen, México, 1979. Estos autores afirman: "La historia está necesariamente basada sobre sistemas de valores, fuera de los cuales no podría haber selección de hechos. Al hacer una selección entre el material disponible, el historiador concede una importancia, un valor particular, a los elementos seleccionados. Su obra puede ser válidamente observada en conjunto como un sistema de valores y de hechos valorizados". 
Por ello, estas tesis no nos Ilevan a inferir que el derecho a la vida, por ejemplo, deba tener un valor mayor en la actualidad que en la Edad Media porque así haya sido, o que tenga mayor sustentabilidad en Noruega que en la India porque efectivamente así se constata. Por el contrario, lo que debe clarificarse, sin dejar resquicio a duda, es que los derechos de los pueblos indígenas (y de otros pueblos o colectivos vulnerables) sólo podrán ser atendidos igualitariamente si se comprende su desarrollo histórico, si se lleva adelante la jerarquización de los derechos reconocidos y se admite que algunos son presupuestos de otros, y si se entiende que no tiene sentido -siguiendo con el ejemplo- privilegiar el derecho a una vida digna si no se contempla que el derecho a la propiedad de la tierra en la que habitan es una condición para su goce.

A lo largo de la historia, y con mayor énfasis en las últimas décadas, se han desarrollado y profundizado diversas teorías antagónicas. Universalismo vs. particularismo, liberalismo vs. fundamentalismo, liberalismo libertario vs. liberalismo igualitario, entre muchas otras, constituyen una serie de pares opuestos que demuestran las tensiones que se generan alrededor de las dimensiones morales y políticas ${ }^{19}$.

Estas tradiciones surgieron en un momento particular para dar cuenta de variados fenómenos sociales que no podían ser entendidos aisladamente. Por el contrario, debían ser estudiados bajo la luz del devenir histórico y su interacción con la realidad circundante.

Pretender construir un sistema internacional de derechos humanos que contemple los derechos específicos de los pueblos indígenas (y dentro de éstos los derechos que demanda en particular cada uno de los pueblos o etnias), sustrayéndolo de la historia de reclamos, de las luchas por la conformación de los Estados, del desarrollo constitucional de las naciones, de los movimientos sociales, es una tarea sin sentido y con escasas consecuencias prácticas valiosas. Principalmente, como enseña la historia, las luchas que han entablado los pueblos indígenas para alcanzar igualdad frente a los otros sujetos se han dado en un marco determinado de tiempo. Pensarlo de otro modo, es un esfuerzo intelectualmente estéril.

La necesidad de "circunstanciar" los valores, dotarlos de una perspectiva histórica, nutrir el análisis con categorías que no permanezcan aisladas sino que interactúen con la realidad que pretenden transformar, es un imperativo de cualquier teoría que tenga la pretensión de aportar elementos que ya no profundicen una igualdad (inexistente) sino que mínimamente intenten generarla.

\section{Derechos colectivos y derechos individuales}

Si existe alguna polémica que atraviesa permanentemente las discusiones alrededor de los pueblos indígenas, que abre brechas aparentemente irreconciliables entre las diferentes posturas teóricas y que se vincula con los debates alrededor del principio de igualdad, es la existente alrededor de los derechos colectivos, su existencia, su importancia y su relación con los derechos individuales que han sido ampliamente reconocidos por todos los instrumentos normativos.

El desconocimiento de los derechos colectivos, o en el mejor de los casos su subordinación a los derechos individuales, ha sido una constante tanto en las posiciones conservadoras como en las posturas liberales más ortodoxas. El fantasma omnipresente de que lo colectivo subsumirá lo individual hasta hacerlo desaparecer, ha operado como una de las principales razones para invocar permanentemente la preeminencia del individuo y la necesidad de resguardar sus derechos ${ }^{20}$.

\footnotetext{
19 Ver Dworkin, Ronald, Ética privada e igualitarismo político, Fernando Vallespín (introd.), Ed. Paidós, Barcelona, 1993 ; Farrell, Martín D., op. cit., 1992; Gargarella, Roberto, op. cit., 1999; Walzer, Michael, Las esferas de la justicia. Una defensa del pluralismo y la igualdad, FCE, México, 1993.

20 Para ver teorías que rechazan la existencia de los derechos colectivos: Garzón Valdés, Ernesto, "El problema ético de las minorías étnicas", en León Olivé (comp.), Ética y Diversidad Cultural, Ed. FCE, México, 1993.
} 
Otro aspecto que ha sido permanentemente ignorado por los análisis clásicos, que sólo reconocen la existencia de derechos individuales y dan la espalda persistentemente a los colectivos, es el de la identidad ${ }^{21}$. Ésta se conforma a través de la lucha por determinados derechos, que se presentan precisamente como derechos colectivos a partir de que los derechos individuales son inadecuados para defenderla.

La identidad de los indígenas siempre ha sido cuestionada, ya sea por aquellos que "buenamente" han intentado asimilarlos a la "sociedad mayor", ya sea por quienes han entendido que su sistema de creencias, su espiritualidad, su cultura, sus formas organizativas son secundarias o irrelevantes para sus elecciones y sus planes de vida.

Tal vez este cuestionamiento permanente esté vinculado con una mayor predisposición y sensibilidad -lo que también tiene componentes históricos- para reconocer a las personas en su individualidad, más que para atribuir relevancia a su membresía a determinado pueblo o nación. No obstante, los diferentes pueblos indígenas, ya sean quechuas, aymaras, mapuches, guaraníes, etcétera, tienen una conciencia clara del significado que para cada uno de ellos adquiere el formar parte de un colectivo.

Por ello la identidad y los derechos colectivos se encuentran engarzados. Porque la lucha por los derechos colectivos no es otra cosa que la lucha por su propia identidad. En la medida en que puedan preservarse determinados derechos inherentes a su condición de pueblos, es mayor la posibilidad de resguardar -y en algunos casos recuperar- sus identidades.

La igualdad, frente a todo esto y como ya ha sido señalado, se convierte en una herramienta de distribución tanto de derechos como de bienes. Si esto es así, una genuina política de reconocimiento debe contemplar como componentes básicos la conquista de los derechos colectivos, la lucha por una identidad diferenciada a la meramente individual y, por último, la reconstrucción de un principio de igualdad que tenga presentes estos elementos para superar la pretendida universalidad y atender las particularidades de estos pueblos.

Superar el desconocimiento y los prejuicios, y comprender que los derechos colectivos representan y significan "más" que la suma de los derechos de individuos, ha sido -y sigue siendo- una ardua tarea. Los derechos colectivos constituyen para los pueblos indígenas herramientas para garantizar su subsistencia y sistema de valores, sus creencias y culturas. Los derechos individuales, entonces, son insuficientes para asegurar el disfrute del plan de vida de los miembros de los pueblos originarios.

Por último, frente a la pregunta inevitable de cuáles derechos deben tener primacía, si los derechos colectivos o los individuales, considero que la respuesta adecuada es que debe merituarse en cada situación, dado que es preciso evaluar cuáles de ellos tienen la característica o la capacidad para corregir los desajustes y desigualdades sociales en un contexto determinado.

\section{Un concepto (genuino) de igualdad (2)}

Derechos emancipatorios como carta de navegación del sistema internacional de derechos $\underline{\text { humanos }}$

Es razonable, explicable y hasta justificable que en un primer desarrollo el individuo haya ocupado un lugar central en el sistema internacional de los derechos humanos, frente a la necesidad

21 Ver Díaz-Polanco, Héctor, op. cit., 2006, pp. 132 y ss.; Gray, John, op. cit., 2001. 
imperiosa de evitar el avance de los Estados sobre sus derechos inalienables. De ese modo, los derechos individuales se convirtieron en la médula del sistema internacional.

Pero con el paso del tiempo, y luego de que el sistema internacional de derechos humanos superara este primer escalón, la centralidad de la persona va dejando lugar paulatinamente a otras demandas tan genuinas y legítimas como las primeras, que sólo pueden ser satisfechas considerando el carácter de colectivo de ciertos sujetos y no la mera suma de individualidades.

Con el objetivo de que el principio de igualdad adquiera sentido para la mirada de los pueblos indígenas, y como modo de no caer en posturas absolutistas o relativistas -ambas impotentes para explicar las profundas desigualdades que los someten-, propondré una categoría que oriente la jerarquización de valores y derechos, que respete la cosmovisión indígena y su sistema de creencias y que, a la vez, no viole el sistema de derechos humanos internacionalmente concebido.

En otras palabras, el respeto a la diversidad se enmarcará en el respeto a una serie de valores y derechos que encuentran su fundamento en la humanidad de los sujetos (ya sean individuales o colectivos). La diferencia estriba en su aplicación, ya que se privilegiarán unos u otros dependiendo de la situación de dichos sujetos, de las dinámicas que establezcan en su relación, de su contexto y del tiempo en que se desarrollen.

A su vez, Ilamaré a esta categoría derechos emancipatorios ${ }^{22}$, dado que es una herramienta generada para que los pueblos indígenas puedan luchar por sus derechos y de ese modo alcanzar una igualdad real. Si fuera preciso presentar una definición de los derechos emancipatorios, tal vez la idea más adecuada sea concebirlos como cartas de navegación que permiten que el sistema internacional de derechos humanos -conformado por el conjunto de derechos identificados y definidos como prioritarios- determine el modo de su aplicación y su prelación frente a sujetos específicos.

Es por ello que las características que definen como emancipatorio a un derecho pueden ser atribuibles, dependiendo del sujeto del que se lo predique, del contexto y del tiempo en que se desarrollen las relaciones o situaciones sociales, a diferentes clases de derechos que adquirirán esa calidad en razón de los requerimientos y las necesidades de los pueblos indígenas.

Para clarificar adecuadamente la idea. El carácter de emancipatorio de un derecho es un instrumento conceptual creado para cumplir una función específica: la de resolver conflictos entre derechos. Califican a un conjunto de derechos que en un lugar y tiempo determinados deben tener primacía sobre otros, para alcanzar una situación tal que permita a algunos sujetos su goce efectivo.

Para ejemplificar, y como un modo de mostrar cómo juegan los derechos emancipatorios, pensemos en un caso concreto en donde colisionen dos derechos: el derecho a la tierra tradicionalmente ocupada por los pueblos originarios frente al derecho a la propiedad privada de un comprador posterior $^{23}$. En nuestra conceptualización, el derecho a la tierra de los pueblos indígenas tendría preeminencia sobre otros derechos en juego, dada su vinculación con la supervivencia de su condición de pueblos.

22 Para ubicar al lector y ejemplificar esta idea, puede pensarse en la independencia norteamericana y en los procesos sociales que se generaron alrededor de ella. La clase de los "acreedores", la burguesía en ascenso en ese período, luchaba por su "derecho a la propiedad". En aquel momento, ese derecho pudo haber sido considerado como un derecho emancipatorio. Para más detalles de ese período, ver Gargarella, Roberto, La justicia frente al gobierno. Sobre el carácter mayoritario del Poder Judicial, Ed. Ariel, Barcelona, 1996.

23 El 14 de febrero de 2007, el pueblo mapuche recuperó un predio de 534 has perteneciente -en los papeles-a Benetton, quien a su vez es "dueño" de aproximadamente 900.000 has en la Patagonia argentina. Actualmente se está librando una controversia judicial en la cual la colisión de estos dos tipos de derecho es evidente. 
Si suscribimos el concepto de igualdad como emancipación no dudaríamos en calificar el derecho a la tierra de los indígenas como un derecho emancipatorio y, por tanto, un derecho que tiene prioridad sobre cualquier otro. Esta es una tesis que difícilmente defenderían otras teorías de la igualdad ya señaladas, que sólo pueden concebir como valiosos a los derechos predicables individualmente. Frente al ejemplo descrito, una igualdad despojada de historicidad, de identidad, del reconocimiento de la existencia de derechos colectivos, tendría dificultades para dejar de admitir el derecho del comprador posterior si cuenta con los respectivos títulos de propiedad.

Por ello, esos derechos que adquieren la calidad de emancipatorios tienen mayor capacidad para corregir los desajustes de sociedades desiguales. De ese modo, la tesis central de este ensayo es que es posible superar la ilusión de trascendentalidad que se refleja en la formulación de derechos universales. A la vez, permite evitar caer en un relativismo que conduce a un debilitamiento de los derechos. Todo ello, a través de la construcción de una nueva categoría conceptual que se convierta para los pueblos indígenas en un instrumento genuino para luchar por sus derechos.

La ilusión de trascendentalidad, cuando trata de profundizar el principio de igualdad, inevitablemente conduce a un etnocentrismo poco deseable. El intento de "colocarse al margen" de cualquier situación real para lograr la formulación de principios universales, genera sólo la construcción de una sociedad desde "determinados parámetros", que se pretenden universales y que en realidad sólo son referentes de una cultura occidental.

Un ingrediente adicional en este análisis, y no menos importante, lo constituye el principio pro persona, concebido como un criterio interpretativo que informa todo el sistema de derechos humanos. Este principio que, en definitiva, se traduce como "estar siempre a favor de la persona" no deja espacio a los derechos colectivos (dentro de los que se incluyen los derechos de los pueblos indígenas), al excluir de su visión las condiciones necesarias para que determinados grupos humanos adquieran la posibilidad de vivir una vida digna ${ }^{24}$.

Si bien se puede argüir que este principio interpretativo da lugar a la protección de todos los derechos reconocidos en los instrumentos internacionales (entre ellos, derechos que se predican de grupos), es inevitable admitir que su formulación es producto de una perspectiva individualista, que se asienta en una concepción abstracta de la persona, concebida aisladamente y no como parte de un contexto.

Un nuevo principio, pro emancipación, operaría entonces jerarquizando valores sin una pretensión de universalidad, evaluando cada situación en su contexto y aportando criterios objetivos fundados en el análisis de las condiciones históricas que se presenten.

\section{El derecho a la propiedad comunitaria de la tierra y el derecho a la autonomía como derechos emancipatorios}

En el caso de los pueblos indígenas, el derecho a la propiedad comunitaria de la tierra, tal como ha sido enfatizado, es un ejemplo de derecho emancipatorio. No es posible pensar que los miembros de los pueblos originarios puedan gozar de otros derechos si no son dueños de su tierra. Ello, no debe llevarnos a pensar que para los pueblos indígenas algunos derechos lo son más que otros. Simplemente que si no se realiza esta suerte de ordenamiento de derechos, se corre el riesgo de volver abstracto, una vez más, al sistema de derechos humanos y al principio de igualdad, al no

\footnotetext{
24 Pinto, Mónica, "El principio pro homine. Criterios de hermenéutica y pautas para la regulación de los derechos humanos", en La aplicación de los tratados sobre derechos humanos por los tribunales locales, Abregú Martín y Courtis Christian (comps.), Editores del Puerto, Buenos Aires, 1997.
} 
tener presentes las diferencias que existen entre las personas y pensar-equivocadamente- que lo que es relevante para mí lo es también para los demás ${ }^{25}$.

Otro ejemplo de derecho emancipatorio, considerando las demandas actuales de los pueblos indígenas, lo constituye el derecho a la autonomía. En general, cuando los pueblos indígenas reclaman su autonomía le asignan un contenido que sólo puede ser entendido como un predicado de grupos que comparten mucho más que un territorio o algunas características comunes. Están hermanados por una concepción del mundo y de la vida que los hace priorizar derechos colectivos por sobre sus propios intereses individuales.

La autonomía para los pueblos indígenas no necesariamente significa separatismo ni independencia de los Estados en los que habitan. Tampoco significa, como en las teorías liberales clásicas, sólo la posibilidad de diseñar los propios planes de vida. Simplemente implica la posibilidad de manejar sus propios recursos, elegir sus cursos de acción, gobernar sus comunidades y lograr que "los otros" respeten su modo de vida como condición imprescindible para su supervivencia como pueblos. El Estado multicultural respeta dentro de su territorio la toma de decisiones de los diferentes pueblos en temas que les atañen y conserva para sí las relaciones internacionales y cierto ámbito de decisión.

Si bien la preeminencia de los derechos colectivos sigue siendo materia de discusión, incluso por aquellos liberales que destacan la importancia del aspecto igualitario de cualquier sociedad democrática y que señalan la relevancia de la autonomía colectiva, es ineludible hacer frente a estos reclamos, que distan de ser pretensiones excesivas o caprichos de algunos pueblos.

Los ejemplos señalados son útiles para ilustrar el modo en que podría jugar, dentro del sistema de derechos humanos, un principio pro emancipación, que cumpliría la misma función que el principio pro persona ya consignado, al regular todo el conjunto de derechos humanos ordenándolo de acuerdo a los efectos que produce sobre aquellos que protege.

\section{Principio de igualdad y pueblos indígenas: su recepción en la administración de justicia y en los instrumentos normativos internacionales}

Para resaltar la importancia que adquiere el principio de igualdad como criterio regulador de las sociedades democráticas, y enfatizar su relevancia para los pueblos indígenas, señalaré cómo ha sido receptado en la resolución de los conflictos dentro de las comunidades (con relación a la administración de justicia "oficial") y cómo ha sido incorporado en los instrumentos normativos internacionales.

\section{Gestión de la conflictividad y administración de justicia}

La administración de justicia destaca como uno de los aspectos paradigmáticos de las instituciones indígenas, que interpela la idea de un tratamiento igualitario. Dentro del esquema institucional que presentan nuestros sistemas democráticos, el aparato de justicia es fundamental, ya que es visualizado como una de las vías más idóneas para resolver los conflictos.

La diversidad valorativa, eje de todo este trabajo, se refleja precisamente en las distintas formas de resolución de conflictos que existen dentro de las comunidades indígenas. Es por esta razón que el respeto de formas autóctonas de administración de justicia adquiere un rasgo privilegiado de reconocimiento de sus sistemas de creencias, de sus pautas culturales, a la vez que funda-

25 Pensar, por ejemplo, que para los pueblos indígenas no asume la misma importancia el derecho a la libertad de expresión que el derecho a la propiedad comunitaria de la tierra. 
mentalmente demuestra la presencia de un Estado multicultural comprometido con el principio de igualdad.

Ese respeto no significa que cualquier tipo de pautas culturales deba ser aceptado. Por el contrario, es importante generar una crítica cultural al interior de las propias comunidades indígenas frente a ciertas prácticas que lesionan la médula básica del sistema de derechos humanos. En este sentido, todos los sistemas axiológicos, tanto indígenas como no indígenas, deben ser dinámicos y abiertos al cambio.

La administración de justicia de acuerdo a sus propias reglas involucra, en términos generales, la posibilidad de determinar qué es lo prohibido y qué es lo permitido, identificar el sistema de sanciones, y establecer propias autoridades para la definición del modo de superar los $\operatorname{conflictos}^{26}$. Por otra parte, también implica que puedan comunicarse en su propia lengua y, fundamentalmente, que se reconozcan sus propios sistemas valorativos.

El reconocimiento de los pueblos indígenas involucra necesariamente el respeto por sus formas de resolución de conflictos. Dado que su propia administración de justicia forma parte de su cultura, resultaría al menos paradójico que se reconociera su sistema cultural sin reconocer ese importante componente.

Es pertinente en este punto destacar un aspecto problemático y permanentemente debatido. Si bien he afirmado que el reconocimiento de sus formas de gestión de la conflictividad reviste un modo en que el principio de igualdad se manifiesta, es insoslayable abordar casos en donde este principio se encuentra fuertemente interpelado.

Así, la primacía que adquiere un derecho por su calidad de emancipatorio podría ceder frente a situaciones que no necesariamente involucran su supervivencia como pueblos. Muchas veces se ejemplifican estas fuertes controversias valorativas con casos límites, como la violencia contra las mujeres ${ }^{27} \mathrm{O}$-en algunas comunidades indígenas- la aplicación de la pena de muerte. Frente a estos casos, no podemos ampararnos en un respeto irrestricto a sus prácticas o en un concepto de "igualdad como emancipación" para admitirlos. En un proceso de diálogo permanente entre diferentes pueblos dentro de nuestros propios Estados, los cambios que produce esa interacción deben ser prohijados. Por último, y dado que los derechos emancipatorios no establecen reglas universales, debe llevarse un análisis cuidadoso dependiendo del factor histórico y del contexto.

Admitir, reconocer y respetar la administración de justicia indígena, diferente a la que utiliza en forma monopólica el Estado, es también admitir la coexistencia de éste con otro sujeto colectivo. Posibilitar esto en la práctica sería la mejor muestra de que el camino a una igualdad plena es posible. Admitir, tanto desde una perspectiva teórica como práctica, que en un mismo Estado la administración de justicia no sea "semejante" para toda la ciudadanía y que el mismo Estado reconozca que parte de ella presenta características tales que amerita la vigencia de un sistema de justicia diferente, no es otra cosa que un impecable ejercicio del trato igualitario.

\footnotetext{
26 Para ilustrar el modo en que puede hacerse realidad el respeto al derecho indígena en armonía con el derecho estatal ver Yrigoyen Fajardo, Raquel, Pautas de coordinación entre el derecho indígena y el derecho estatal, Fundación Myrna Mack, Guatemala, 1999.

27 Combinar el abordaje de cuestiones de género con la problemática indígena es una empresa extremadamente delicada. A pesar de que es necesario discutir sobre derechos de las mujeres dentro de las comunidades indígenas, es preciso tener presente que estos aspectos también han sido formulados y reelaborados desde una perspectiva occidental. Por lo cual, la concientización de la importancia de los derechos de las mujeres debe discutirse e instalarse entendiendo su propio sistema de creencias y sus pautas culturales, e iniciando paulatinamente algunos procesos de cambio que son necesarios.
} 
Convenio 169 de la OIT, Declaración Universal de los Derechos Humanos y Declaración de las Naciones Unidas sobre los Derechos de los Pueblos Indígenas

Las discusiones teóricas citadas en los párrafos precedentes sobre el principio de igualdad no han concluido, y se puede afirmar que estamos lejos aún de alcanzar un consenso alrededor de su contenido e implicancias. No obstante, se han plasmado algunas herramientas normativas que consagran un principio de igualdad entendido principalmente como aquel que privilegia la diferencia.

Transitamos desde las discusiones sostenidas alrededor de la Declaración Universal de los Derechos Humanos, en donde se enfatizó la necesidad de universalizar valores para igualar las circunstancias del sujeto individual -concebido como la unidad de la cual derivan todos los derechos-, hasta los debates más contemporáneos, en donde el surgimiento de sujetos colectivos imprime otros matices a la protección de derechos.

No sólo las Constituciones de la mayoría de los Estados latinoamericanos han receptado en sus formulaciones un reconocimiento explícito de la existencia -y preexistencia- de los pueblos indígenas y, por ende, la necesaria protección de sus derechos, sino que en las últimas décadas se han perfeccionado algunos instrumentos normativos internacionales tendientes a asegurar la protección de formas de vida que habían sido, en el mejor de los casos, ignoradas.

El Convenio 169 de la OIT (Organización Internacional del Trabajo) es la herramienta normativa por excelencia en la defensa de los derechos de los pueblos indígenas. En ella se reconocen derechos colectivos básicos, como la propiedad comunitaria de la tierra, la libre determinación de los pueblos, el uso de la lengua, los derechos de participación, entre otros ${ }^{28}$. La idea principal que subyace a su formulación es la necesidad de resguardar formas de vida a través de herramientas que defienden los derechos colectivos.

El Convenio 169 de la OIT se promulga cuatro décadas después de la Declaración Universal de los Derechos del Hombre, lo que permite seguir el rastro a los cambios de concepción que se producen en el seno de las propias organizaciones internacionales, en la conformación de los Estados y, en definitiva, en el escenario político. Cambios que obligan a un replanteo de la inserción de los pueblos indígenas en el contexto internacional. Por una parte, avanza conceptualmente de manera notable con respecto al Convenio que le precede y que data de 1957, consagrando un paradigma superador de interacción con los pueblos. En segundo lugar, coloca en la agenda de los foros internacionales las discusiones alrededor de los derechos de los pueblos indígenas. En tercer lugar, dota a los pueblos indígenas de un instrumento imprescindible para la defensa de sus derechos.

Citar esta herramienta normativa es relevante en la medida que contempla un principio de igualdad que tiene presentes los intereses y demandas de sujetos colectivos (los pueblos indígenas). Asimismo, cotejarla con la Declaración de 1948 permite dejar expuestas las diferentes concepciones imperantes para demostrar lo dinámico de las relaciones entre sujetos y Estado, así como la centralidad adquirida por colectivos que luchan denodadamente para que sus derechos como pueblos sean reconocidos.

También en este instrumento -como en las cláusulas incorporadas en las últimas reformas constitucionales de los Estados latinoamericanos- se pone de manifiesto la necesidad de bajar a tierra las discusiones Ilevadas adelantes en diferentes planos morales, iusfilosóficos y políticos. En ese

28 Para una presentación más extensa de estos temas ver Ramírez, Silvina, La Guerra Silenciosa. Despojo y Resistencia de los Pueblos indígenas, Ed. Capital Intelectual, Buenos Aires, 2006. 
sentido, la defensa a rajatabla de la igualdad para los pueblos indígenas significa sin lugar a dudas la posibilidad de defender sus derechos, estos últimos valorados de acuerdo al plexo axiológico de los propios indígenas.

Finalmente, no puedo dejar de mencionar la Declaración de las Naciones Unidas sobre los Derechos de los Pueblos Indígenas promulgada en 2006. En ella se vuelven a plasmar algunas de las discusiones de las últimas décadas. No es casual que su promulgación haya tomado once años (once períodos de sesiones del grupo de trabajo) y que sólo haya logrado ratificar una concepción del principio de igualdad todavía amarrada a la idea de integralidad de los Derechos Humanos, que no avanza en la jerarquización de algunos sobre otros (dependiendo de la realidad que están regulando) y que carece de las distinciones necesarias para maximizar sus ámbitos de protección ${ }^{29}$.

Si bien la Declaración reconoce plenamente, entre otros, el derecho de los pueblos originarios a la no discriminación y a la libre determinación, vinculando los derechos de autonomía y autogobierno a las cuestiones relacionadas con sus asuntos internos, este reconocimiento no implica atribuirles jerarquía al conjunto de derechos contemplados ${ }^{30}$. Como ya destaqué, ello significa en definitiva debilitar la fuerza de los derechos indígenas al considerarlos en un mismo nivel que el resto de los derechos individuales, a la vez que tampoco resalta algunos matices imprescindibles frente a la multitud de derechos indígenas reconocidos. Así, se convierte a la Declaración en un instrumento coherente en su concepción general pero carente de la utilidad práctica necesaria a la hora de llevar adelante la defensa concreta de los pueblos.

\section{Conclusiones}

Si no comprendemos profundamente el significado y las diferentes dimensiones del principio de igualdad; si no realizamos una revisión de las últimas discusiones alrededor de su conceptualización; si no concluimos que esas discusiones deben ser acompañadas de una genuina vocación de transformación de las realidades, sólo llevaremos adelante una reflexión superficial que no modificará en ningún sentido la vida de los pueblos indígenas.

Para estos pueblos, el principio de igualdad es mucho más que una abstracción. Comienza con el reconocimiento de su derecho a la no discriminación y transita hacia cuestiones más sustantivas que se vinculan con la protección de sus derechos más básicos. El abordaje del principio de igualdad debe alejarse de las posturas paternalistas y debe abandonar definitivamente la pretensión asimilatoria, para concentrarse en el objetivo principal: la aceptación, por parte de personas y Estados, de que los pueblos indígenas - "los otros"- merecen ser tratados teniendo

29 Para una conceptualización de la perspectiva integral de los derechos humanos ver Gros Espiell, Héctor, Derechos Humanos, Cultural Cuzco S.A. Editores, Lima, 1991, p. 17.

30 Así, la Declaración dispone:

“Art. 42: Los derechos reconocidos en la presente declaración constituyen las normas mínimas para la supervivencia, la dignidad y el bienestar de los pueblos indígenas del mundo.

Art. 43: Todos los derechos y libertades reconocidos en la presente Declaración se garantizan por igual al hombre y a la mujer indígenas.

Art. 44: Nada de lo contenido en la presente Declaración se interpretará en el sentido de que limite o anule los derechos que los Pueblos indígenas tienen en la actualidad o pueden adquirir en el futuro.

Art. 45, apartado 3: Las disposiciones mencionadas en la presente Declaración se interpretarán con arreglo a los principios de la justicia, la democracia, el respeto de los derechos humanos, la igualdad, la no discriminación, la buena administración pública y la buena fe".

Como puede verse, se tiene muy presente el principio de igualdad, pero se presenta de una forma tan genérica que, en esos términos, la expresión de respeto a la diversidad resulta de muy difícil concreción. 
presentes sus propias elecciones, respetando su autonomía y redefiniendo día a día cuál es la mejor interacción posible.

Para juzgar la multiculturalidad de un Estado y evaluar hasta qué punto ese Estado respeta un principio de igualdad coherente con el respeto a la diversidad, debemos contar con un instrumento conceptual que despeje discusiones teóricas y tenga incidencia efectiva en la vida de los pueblos.

El instrumento ideado en este trabajo para cumplir esa función es el concepto de derechos emancipatorios. Esta calidad emancipatoria puede predicarse de cualquiera de los derechos, siempre y cuando se utilice para privilegiar lo que en su momento se considera como imprescindible para la consolidación de los pueblos originarios. Asimismo, tiene la capacidad de equilibrar situaciones en la medida en que genera condiciones para que la igualdad real, tangible y concreta sea posible.

Finalmente, también pretende constituirse en un aporte concreto a la lucha de los pueblos originarios por sus derechos. En ese sentido, esta lucha siempre debe enmarcarse en la búsqueda de una sociedad más igualitaria, que deje atrás los procesos de exclusión y que preste atención a las necesidades de los colectivos. Los pueblos indígenas y su particular cosmovisión del mundo generan requerimientos diferentes que deben ser atendidos por un genuino Estado multicultural, que abra sus puertas a lo diverso a través de políticas públicas que apunten a superar las tensiones y contradicciones señaladas en este trabajo. 